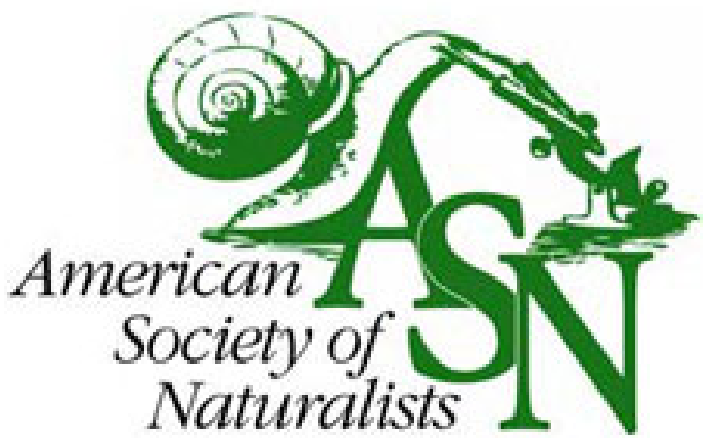

The University of Chicago

The Nested Assembly of Plant Facilitation Networks Prevents Species Extinctions Author(s): Miguel Verdú and Alfonso Valiente-Banuet

Reviewed work(s):

Source: The American Naturalist, Vol. 172, No. 6 (December 2008), pp. 751-760

Published by: The University of Chicago Press for The American Society of Naturalists

Stable URL: http://www.jstor.org/stable/10.1086/593003

Accessed: $31 / 10 / 2012$ 08:26

Your use of the JSTOR archive indicates your acceptance of the Terms \& Conditions of Use, available at http://www.jstor.org/page/info/about/policies/terms.jsp

JSTOR is a not-for-profit service that helps scholars, researchers, and students discover, use, and build upon a wide range of content in a trusted digital archive. We use information technology and tools to increase productivity and facilitate new forms of scholarship. For more information about JSTOR, please contact support@jstor.org. 


\title{
The Nested Assembly of Plant Facilitation Networks Prevents Species Extinctions
}

\author{
Miguel Verdún ${ }^{1, \star}$ and Alfonso Valiente-Banuet ${ }^{2, \dagger}$
}

1. Centro de Investigaciones sobre Desertificación (Consejo Superior de Investigaciones Científicas-Universitat de ValènciaGeneralitat Valenciana), Apartado Oficial 46470, Albal, Valencia, Spain;

2. Departamento de Ecología de la Biodiversidad, Instituto de Ecología, Universidad Nacional Autónoma de México, Apartado Postal 70-275, 04510 México, Distrito Federal, Mexico

Submitted May 30, 2008; Accepted June 16, 2008;

Electronically published October 23, 2008

Online enhancement: appendix table.

ABSTRACT: Facilitation is a positive interaction assembling ecological communities and preserving global biodiversity. Although communities acquire emerging properties when many species interact, most of our knowledge about facilitation is based on studies between pairs of species. To understand how plant facilitation preserves biodiversity in complex ecological communities, we propose to move from the study of pairwise interactions to the network approach. We show that facilitation networks behave as mutualistic networks do, characterized by a nonrandom, nested structure of plant-plant interactions in which a few generalist nurses facilitate a large number of species while the rest of the nurses facilitate only a subset of them. Consequently, generalist nurses shape a dense and highly connected network. Interestingly, such generalist nurses are the most abundant species in the community, making facilitation-shaped communities strongly resistant to extinction, as revealed by coextinction simulations. The nested structure of facilitative networks explains why facilitation, by preventing extinction, preserves biodiversity.

Keywords: biodiversity conservation, complex networks, facilitation, nestedness.

Determination of the mechanisms driving the species composition and maintenance of species diversity in plant

* Corresponding author; e-mail: miguel.verdu@uv.es.

† E-mail: avali@servidor.unam.mx.

Am. Nat. 2008. Vol. 172, pp. 751-760. (c) 2008 by The University of Chicago. 0003-0147/2008/17206-50504\$15.00. All rights reserved.

DOI: $10.1086 / 593003$ community assemblages is central to ecology, but we still have limited knowledge of the complexity inherent in multispecies systems in which each species interacts with others (Miller 1994; Callaway 2007). Such complexity has been historically handled by studying pairwise (usually competitive) interactions and considering that community properties are determined only by the intrinsic properties of their constituent species (Connell 1983; Levins and Lewontin 1985; Crawley 1997). However, during the past two decades, considerable evidence has accumulated showing not only competitive but also facilitative interactions, in which at least one of the participants is benefited and neither is harmed (Stachowicz 2001). Facilitation is a ubiquitous interaction in terrestrial and aquatic communities worldwide, occurring when one organism ameliorates the local environment for another, especially under harsh conditions such as thermal, water, or nutrient stress (Callaway 1995; Bruno et al. 2003). Ecological communities, such as mangrove forests, coral reefs, seagrass beds, conifer forests, grasslands, and semiarid plant communities, are governed by the facilitation afforded to beneficiary species by habitat amelioration produced by benefactor species (Bruno and Bertness 2001). In some plant communities, more than $90 \%$ of the species recruit successfully only beneath the canopies of perennial nurse plants and therefore are maintained via facilitation (McAuliffe 1988; Valiente-Banuet and Verdú 2007). Such interactions show a high degree of species specificity in relationships (Callaway 1998). Likewise, facilitation has played a central role over evolutionary time in conserving ancestral regeneration niches while preserving global biodiversity (Valiente-Banuet et al. 2006). Although this evidence emphasizes the importance of including facilitation in the mainstream of ecological theory (Bruno et al. 2003; Tirado and Pugnaire 2005), to unravel the effects of facilitation on biodiversity maintenance ecologists will have to move away from the study of pairwise interactions in order to uncover properties that may emerge when many species grow together (Levins and Lewontin 1985). In less complex communities, such as those inhabiting rocky intertidal zones, many studies have successfully incorporated multiple species interactions- 
including facilitation - and have clearly demonstrated that community assembly cannot be understood as the sum of the pairwise species interactions (Bertness et al. 2006; van de Koppel et al. 2006). These studies have challenged the traditional view of multiple benefactor species as being redundant in the assembly of the community (Bruno and Bertness 2001). Far from being redundant, multiple benefactors may act synergistically and set off a facilitating cascade (Altieri et al. 2007).

To visualize the complexity arising from multiple interactions, we propose to conceive of plant communities as ecological networks in which species interact with others connected to one or more other species. A facilitative network would be constituted by benefactor (nurse) species interacting with beneficiary (facilitated) species. Networks for plant-animal mutualisms have recently been shown to have a nonrandom, nested structure in which generalists interacting with other generalists form a core of interacting species; specialists interact with particular subsets of the generalist species, and interactions between specialists are very rare (Bascompte et al. 2003; Guimarães et al. 2006). In addition, the frequency distribution of links per node of these networks departs from randomness. In a random network, the probability that a node collects links (i.e., interactions) is determined by chance, and therefore hubs (i.e., hyperconnected nodes) do not exist. In real networks, hubs exist because some nodes are more prone to collect links. When the cumulative distribution of links per node is plotted in a log-log scale, random networks are characterized by an exponential distribution, while real networks best fit a power-law function (i.e., a few nodes collect many links, and most nodes collect few links) or a truncated power-law function (i.e., a few nodes collect many links, but their number decays exponentially once a certain number of connections per node is reached; Jordano et al. 2003; Montoya et al. 2006).

Knowing the architecture of facilitation networks should provide insights into both the relative importance of individual species in the community assemblage and the mechanism by which facilitation maintains biodiversity (Valiente-Banuet et al. 2006). If facilitation networks show a nested structure, then a few generalist nurses are driving community organization by facilitating many plant species, while specialist nurses facilitate only a highly restricted subset of the same plant species. At the same time, nestedness would explain how facilitation maintains biodiversity, given that this network property makes communities robust against extinction (Memmott et al. 2004).

Here we expand on this approach and show that the facilitative networks between nurses and facilitated plants in seven arid plant communities behave as mutualistic networks do, characterized by a nonrandom, nested structure of plant-plant interactions. Consequently, generalist nurses shape a dense and highly connected network whose architecture confers robustness against extinction to plant communities and explains thus how facilitation maintains biodiversity.

\section{Methods}

To conduct this analysis, we collected information on facilitative interactions in seven Mexican arid and semiarid plant communities strongly shaped by facilitation. Three of these communities were studied by Valiente-Banuet and Verdú $(2007,2008)$ and are located in the tropical Tehuacán-Cuicatlán Valley: Tetechera1, Tetechera2, and Cardonal. The other four communities are located outside the tropics in the Sonoran Desert of Baja California, along a latitudinal gradient ranging from $24^{\circ}$ to $28^{\circ} 50^{\prime} \mathrm{N}$. The two southernmost communities are located in Punta Arena de la Ventana $\left(24^{\circ} 01^{\prime} \mathrm{N}, 109^{\circ} 52^{\prime} \mathrm{W}\right)$. The first, Parenal, grows on sandy soils in a sarcocaulescent desert dominated by the columnar cactus Pachycereus pringlei and the trees Prosopis articulata and Olneya tesota (Shreve 1951), whereas the second, Parena2, grows on clayey-loamy soils and is dominated by the trees Fouquieria diguetti, Bursera microphylla, and Cyrtocarpa edulis (Valiente-Banuet et al. 1995). The third community, a creosote bush scrub dominated by Larrea tridentata, Ambrosia dumosa, and Stenocereus gummosus, and the fourth, a sarcocaulescent shrubland dominated by the trees Fouquieria columnaris, Pachycormus discolor, and Pachycereus pringlei and the shrubs Ambrosia bryantii and Ambrosia chenopodiifolia (Vizcaino1 and Vizcaino2, respectively), lie within the Vizcaino region $\left(27^{\circ} 33^{\prime}-28^{\circ} 45^{\prime} \mathrm{N}, 113^{\circ} 12^{\prime}-113^{\circ} 58^{\prime} \mathrm{W}\right.$; Shreve 1951).

The mechanisms underlying facilitation in our study areas were studied by Valiente-Banuet and Ezcurra (1991) and C. Silva-Pereyra and A. Valiente-Banuet (unpublished data), who experimentally determined that the nurse-plant effect is chiefly the result of differential seedling survival in shaded microsites where temperatures and evaporative demands are lower than in the open ground. Higher soil fertility beneath nurse canopies was of secondary importance in such areas.

In each community, we counted the number of seedlings and saplings (up to $30 \mathrm{~cm}$ high) growing beneath canopies and in open spaces along four transects of $1,000 \mathrm{~m}^{2}$ each. The percentage of cover occupied by each nurse species within transects was also measured. The total area sampled for the seven studied communities was $28,000 \mathrm{~m}^{2}$.

Facilitation interactions in each community were depicted as networks consisting of two sets of nodes (nurses and facilitated plants) linked by interactions between any species pair. Thus, we constructed a matrix containing the number of individuals of each beneficiary species occur- 
ring beneath each nurse species. This quantitative matrix was transformed in a qualitative $0 / 1$ matrix to calculate the parameters of the networks by describing the number of species and interactions as well as how much (connectance) and how (nestedness) these species are connected with each other (see table 1). Connectance is the fraction of pairs of nurses and facilitated plant species that directly interact. Nestedness was calculated as $N=$ $(100-T) / 100$, in which $T$ is the matrix temperature (a measure of how the presence/absence pattern departs from perfect nestedness), as implemented in the software ANINHADO (Guimarães and Guimarães 2006; see also Atmar and Patterson 1993). Perfectly nested matrices have $N$ values of 100 , and different null models are available to test whether the nestedness degree statistically departs from the random expectation, given the particular network features (Bascompte et al. 2003). We fitted 1,000 replicates of the null model 2 available in the ANINHADO software to test whether our communities were significantly nested. Under this null model, the probability that a facilitated plant species $i$ interacts with a nurse plant species $j$ depends on the observed number of interactions of both species (Guimarães and Guimarães 2006). Because the number of interactions per species is correlated with species abundance (see "Results"), this model also controls for potential sampling bias in which asymmetrical patterns of interactions are generated only by differences in species abundance (Guimarães et al. 2006).

As matrix temperature has been recently criticized because of its high Type I error, we also calculated one of the algorithms (the Brualdi and Sanderson discrepancy index) and compared it with one of the null models (fixed row totals, equiprobable column totals) proposed by Ulrich and Gotelli (2007), as a compromise between the power to detect nestedness (89\%) and Type I error (23\%). The algorithm is a count of the number of discrepancies (absences or presences) that must be deleted to produce a perfectly nested matrix (Brualdi and Sanderson 1999; Ulrich and Gotelli 2007). The null model reshuffles species, maintaining row totals and allowing column totals to vary randomly (Gotelli 2000; Ulrich and Gotelli 2007).

The cumulative frequency distributions of links per node (i.e., the number of facilitated plant species per nurse species) were fitted to exponential, power-law, and truncated power-law distributions by using the maximum likelihood estimators as implemented in the "brainwaver" package for R (http://www.wbic.cam.ac.uk/ sa428/). We explored whether nurse abundance was related to the ability to collect links by fitting a generalized linear model with Poisson distribution of errors and with the number of facilitated species as a dependent variable and the nurse cover as an independent variable.

Finally, we simulated the extinction of facilitated plant species following nurse extinction by removing nurse species from the qualitative matrix and observing which facilitated plant species were left without a regeneration niche as a result. Facilitated species were considered to be extinct in each study community upon loss of all nurse species under which they regenerate. Following this rationale, nurse extinction was simulated using two opposite sequences. First, we removed nurse species in order of connectedness from the least to the most connected nurses, while the other simulation followed the opposite extinction sequence (see Memmott et al. 2004 for a similar procedure). The realism of the extinction simulations is based on the assumptions that (1) facilitated plants are strongly dependent on the nurses for their survival and (2) such dependence is species specific (i.e., beneficiary species are associated with specific benefactors, creating the niche requirements, and are not associated only with the most abundant nurses). If these relationships were not specific, then the extinction of a particular nurse species might lead to increased abundance of other nurse species, and the facilitated plants would then shift their distribution to be associated with these newly abundant nurses.

The first assumption is realistic because an average of $97 \%$ of the species and $96.5 \%$ of the individuals in the Tehuacán communities recruit under nurses (see table 1

Table 1: Regeneration requirements of species in four extratropical arid communities in the Sonoran Desert of Baja California, Mexico

\begin{tabular}{|c|c|c|c|c|c|c|c|c|c|}
\hline Community & $\begin{array}{c}\text { No. } \\
\text { species }\end{array}$ & $\begin{array}{c}\text { No. } \\
\text { nurse } \\
\text { species }\end{array}$ & $\begin{array}{c}\text { Species } \\
\text { facilitated }^{\mathrm{a}} \\
(\%)\end{array}$ & $\begin{array}{c}\text { No. individuals } \\
\text { beneath } \\
\text { nurse plants }\end{array}$ & $\begin{array}{l}\text { No. individuals } \\
\text { in open } \\
\text { space }\end{array}$ & $\begin{array}{c}\text { Total plant } \\
\text { cover } \\
(\%)\end{array}$ & $\begin{array}{c}\text { Open ground } \\
\text { cover } \\
(\%)\end{array}$ & $\chi^{2}$ & $P$ \\
\hline Parenal & 43 & 16 & 100 & 1,100 & 3 & 66 & 34 & 559.2 & $<.00001$ \\
\hline Parena2 & 32 & 18 & 97 & 874 & 129 & 70 & 30 & 140.3 & $<.00001$ \\
\hline Vizcainol & 35 & 13 & 94 & 667 & 67 & 43 & 57 & 686.3 & $<.00001$ \\
\hline Vizcaino2 & 34 & 19 & 90 & 744 & 61 & 55 & 45 & 455.5 & $<.00001$ \\
\hline
\end{tabular}

Note: The $\chi^{2}$ test is significant if the observed number of individuals (all species pooled) recruiting under nurses is higher than expected by the proportion of area occupied by plant cover.

a A species was considered to be facilitated when the percentage of individuals recruiting under nurses was greater than expected by the percentage of the nurse cover in the community with respect to open space. Individual $\chi^{2}$ tests were conducted only for the dominant species. 
in Valiente-Banuet and Verdú 2007). Similarly, an average of $95.2 \%$ of the species and $92.5 \%$ of the individuals in the Sonoran Desert communities recruit under nurses (table 1).

To test the second assumption about the specialization of the interactions, we calculated the standardized specialization index $H_{2}^{\prime}$ and compared it with a null model in which the number of interactions for each species is given by its abundance but interactions are assigned randomly. For each species, the specialization index $d^{\prime}$ indicates how specialized a given species is in relation to partner abundance (Blüthgen et al. 2006). These indices are based on quantitative matrices reflecting the frequency of occurrences (i.e., the number of individuals of each beneficiary species occurring beneath each nurse species). This method usually considers interaction frequency as a measure of partner abundance because abundant species tend to have more interactions than rare ones. However, independent estimates of abundance should be implemented in the analysis when interaction frequency in the network is not a good estimator of abundance. In our case, because nurse cover is significantly correlated with the number of interactions a species establishes (see "Results"), the specialization indexes $d^{\prime}$ calculated with the two estimates of abundances (nurse cover and frequency of interactions) are significantly correlated $(P<.01$ for all seven communities; data not shown). All these analyses were run with the help of Nils Blüthgen's Web server to analyze specialization in bipartite networks (http://nils.mib.man .ac.uk/ nils/stat) and the bipartite package for R (Blüthgen et al. 2006).

\section{Results}

The number of nurse species in each community ranged from 13 to 31, and the number of facilitated plants ranged

Table 2: Descriptive statistics of the study communities

\begin{tabular}{lcccccc}
\hline $\begin{array}{l}\text { Biogeographical } \\
\text { region, community }\end{array}$ & $F$ & $N$ & $I$ & $C$ & $\mathrm{Ne}(T)^{\mathrm{a}}$ & $\mathrm{Ne}(\mathrm{BR})^{\mathrm{a}}$ \\
\hline $\begin{array}{l}\text { Intertropical: } \\
\text { Tetechera1 }\end{array}$ & 52 & 21 & 171 & 15.7 & .95 & 50 \\
$\quad$ Cardonal & 50 & 31 & 268 & 17.3 & .88 & 104 \\
$\quad$ Tetechera2 & 65 & 27 & 374 & 21.3 & .90 & 120 \\
Extratropical: & & & & & & \\
$\quad$ Parena1 & 40 & 16 & 189 & 29.5 & .88 & 47 \\
Parena2 & 31 & 18 & 143 & 25.6 & .92 & 37 \\
Vizcaino1 & 35 & 13 & 158 & 34.7 & .89 & 33 \\
$\quad$ Vizcaino2 & 30 & 19 & 172 & 30.2 & .87 & 44 \\
\hline
\end{tabular}

Note: $F=$ number of facilitated plant species. $N=$ number of nurse plant species. $I=$ number of interactions. $C=$ connectance $=100 I /(F \times N)$. $\mathrm{Ne}(T)=$ nestedness calculated as matrix temperature. $\mathrm{Ne}(\mathrm{BR})=$ nestedness calculated as Brualdi and Sanderson (1999) discrepancy index (see "Methods" for explanations of the algorithms and the null model).

${ }^{a} P<.05$ in all cases. between 30 and 65 (table 2), yielding an average ratio of facilitated to nurse plants of $2.14 \pm 0.48$, which is similar to that in most plant-animal mutualistic networks (Guimarães et al. 2007). Nurses and facilitated plant species were highly connected (mean connectance $\pm \mathrm{SE}=$ $24.9 \pm 2.68$; see fig. 1); that is, they had more than twice the average connectance of pollination networks $(11.89 \pm 3.41$; Olesen et al. 2006; $F=12.94$, df $=1,42$, $P<.001)$. The taxonomic affiliation of the most connected species strongly differed between communities (see the appendix in the online edition of the American Naturalist).

When matrix temperature was used, the seven facilitation networks were significantly more nested than would be expected by chance (table 2). The same result was found when the Brualdi and Sanderson discrepancy index was tested against the null model that reshuffled species, maintained row totals, and allowed column totals to vary randomly (table 2). On average, facilitation networks were nested $(0.897 \pm 0.027$, mean \pm SE) to a degree similar to that for seed dispersal and pollination networks $(0.843 \pm 0.021, \quad F=1.60, \quad \mathrm{df}=1,32, \quad P=.21 \quad$ and $0.853 \pm 0.022, F=1.002, \mathrm{df}=1,30, P=.32$, respectively; Bascompte et al. 2003). The degree of nestedness in the communities was independent of species richness $(r=-0.05, n=7, P=.91)$ or biogeographical region (intertropical vs. extratropical; $F=1.51, \mathrm{df}=1,5, P=$ .27).

The best fits of the cumulative frequency of the number of facilitated plants per nurse species followed a truncated power-law function, indicating that as the number of facilitated plants reaches the critical truncation value, the probability of finding more connected nurses drops faster than expected from a power-law function (fig. 2). The number of species facilitated by each nurse species was significantly correlated with the degree of nurse cover, and this result was consistent in all the communities (table 3). However, specialization indexes weighted by species abundance revealed a significant departure from the null model in all seven communities, indicating that the number of interactions for each species is not determined only by its abundance (table 4).

The extinction simulations showed two different results, depending on the sequence of nurse extinction. The richness of facilitated plants remained virtually unaffected until removal of the last, most-connected nurses when nurses were removed from least to most connected species (fig. 3). In contrast, a linear extinction of facilitated plants occurred when nurses were removed from the most to the least connected species (fig. 3).

\section{Discussion}

Plant communities governed by facilitation are assembled in networks with architecture comparable to that of plant- 


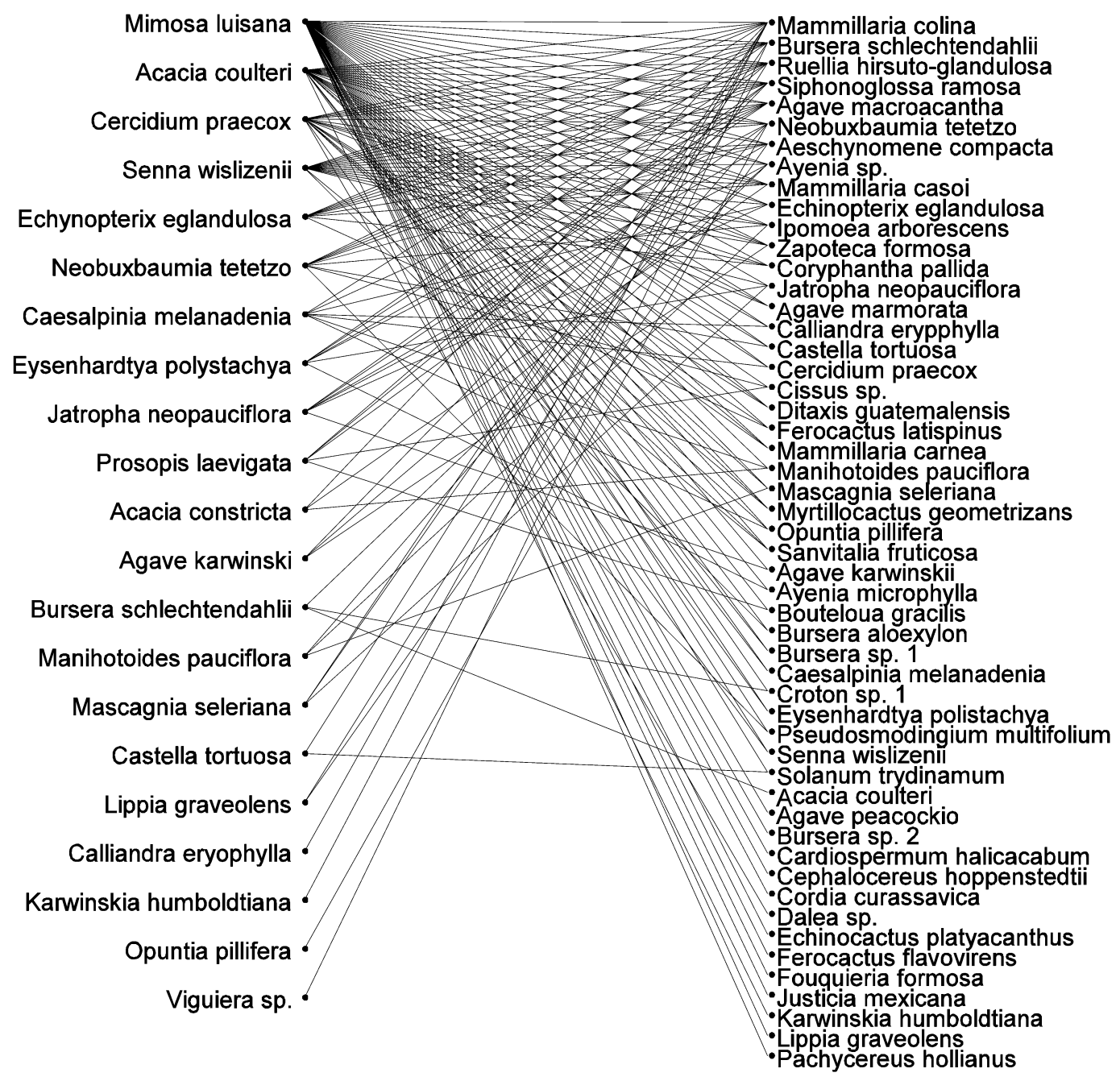

Figure 1: Facilitation network of Tetecheral community, showing the interactions between nurses (left) and their facilitated plants (right).

animal mutualistic networks (Bascompte et al. 2003; Olesen et al. 2006; Vázquez and Aizen 2006). In other words, facilitation communities are assembled as networks with a significant nested structure in which species are highly connected with each other. In facilitative networks, high nestedness is the consequence of a core of generalist nurses facilitating many plant species and the rest of the nurses facilitating a limited subset of the same species. As in mutualistic networks, the number of generalist nurses decays faster than expected from a power law. The salient result is that our communities are structured by processes that go beyond the intrinsic properties of their constituent species. All the above-mentioned properties shed light on the ecology and evolution of interspecific interactions and provide useful tools for species conservation (AlmeidaNeto et al. 2007), as we discuss below.

\section{Ecological and Evolutionary Processes}

The emerging properties we have described were consistent across the different communities, despite their biogeographical position (intertropical vs. extratropical) and specific composition. The consistency of the patterns that emerged at the community level is striking because facilitative interactions may be mediated by a plethora of different mechanisms (Callaway 2007). Whatever the mechanism involved, facilitation can ultimately be seen as a force maintaining suitable regeneration niches of beneficiary species (Valiente-Banuet et al. 2006).

Suitable niches depend on the specific requirements of each facilitated plant species, and each nurse may modify the niche in different ways (i.e., shading, increasing soil moisture and fertility, etc.; see Callaway 2007 for an ex- 


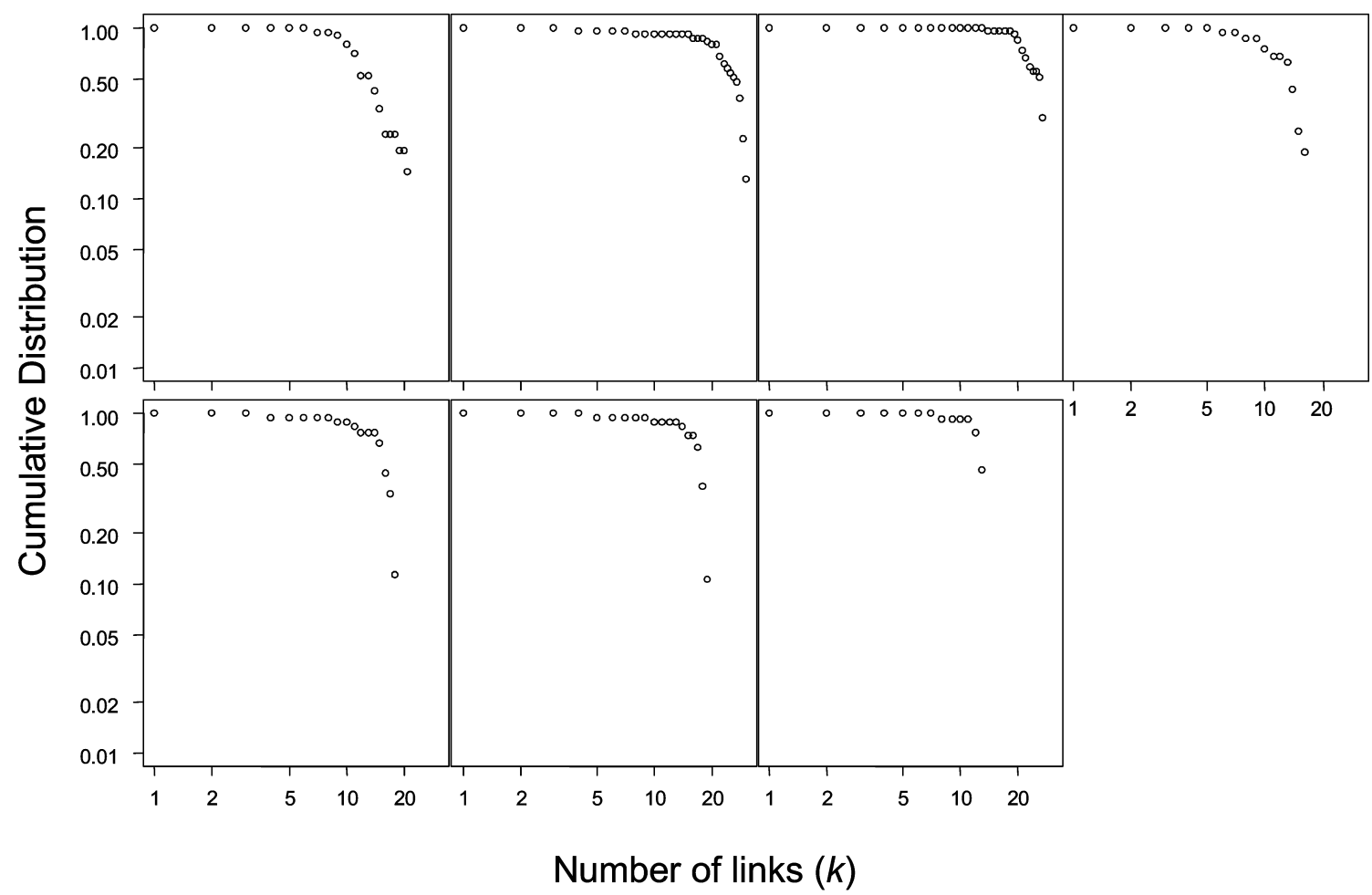

Figure 2: Cumulative frequency distributions of the number of facilitated plant per nurse species in the seven study communities. From left to right: top, Tetechera1, Cardonal, Tetechera2, and Parena1; bottom, Parena2, Vizcaino1, and Vizcaino2. The best fit for all the curves is the truncated power law.

tensive review). Because the niche provided by the nurse must match the niche required by the facilitated species, the relationships between nurses and facilitated plants in facilitation networks are necessarily species-specific to a significant degree (Callaway 1998). Indeed, previous experimental studies have shown that the performance of facilitated seedlings is dependent on the identity of the nurse (Carrillo-García et al. 2000; Puerta-Piñero et al. 2006). For instance, in one of our Sonoran communities (Parena1), seedlings of the cactus Pachycereus pringlei showed differential survival while growing in four different soils obtained from beneath different plant nurses (Carrillo-García et al. 2000). Similarly, in one of our Tehuacán communities (Tetechera2), seedling establishment and survival of the facilitated columnar cactus Neobuxbaumia mezcalaensis was highest when planted under the most connected nurse species (J. P. Castillo and A. ValienteBanuet, unpublished data). Similar species-specific effects of the facilitation mechanisms can be found in Mediterranean ecosystems (Puerta-Piñero et al. 2006).

An analogy exists with the nested distributional pattern of annual cobble beach plants facilitated by Spartina alterniflora beds in which the biota at species-poor sites (i.e., small Spartina beds) represents a subset of those inhabiting richer sites (large Spartina beds; Bruno 2002). Bruno experimentally demonstrated that nestedness can be explained by a mismatch between the niche requirements of the rare facilitated species and the niche provided by the small Spartina beds (Bruno 2002). If a single nurse species cannot provide suitable niches for every facilitated plant

Table 3: Number of plant species facilitated by nurse species increases with nurse abundance (\% cover occupied in each community)

\begin{tabular}{ll}
\hline Community & Nurse cover \\
\hline Tetechera1 & $.07 \pm .01^{\star * *}$ \\
Cardonal & $.07 \pm .01^{\star * *}$ \\
Tetechera2 & $.16 \pm .03^{\star * *}$ \\
Parena1 & $.08 \pm .02^{\star *}$ \\
Parena2 & $.08 \pm .02^{\star * *}$ \\
Vizcaino1 & $.21 \pm .04^{\star * *}$ \\
Vizcaino2 & $.13 \pm .03^{\star *}$ \\
\hline
\end{tabular}

Note: Entries show estimates $( \pm \mathrm{SE}$ ) of the Poisson generalized linear model.

** $P<.01$.

*** $P<.001$. 
Table 4: Weighted mean specialization index of nurse $\left(d_{\text {nurse }}^{\prime}\right)$ and facilitated plant $\left(d_{\text {facilitated }}^{\prime}\right)$ species and overall specialization index at the network level $\left(H_{2}^{\prime}\right)$

\begin{tabular}{lccc}
\hline Community & $d_{\text {nurse }}^{\prime}$ & $d_{\text {facilitated }}^{\prime}$ & $H_{2}^{\text {aa }}$ \\
\hline Tetechera1 & .17 & .13 & .186 \\
Cardonal & .16 & .14 & .166 \\
Tetechera2 & .14 & .12 & .128 \\
Parena1 & .17 & .10 & .176 \\
Parena2 & .14 & .13 & .142 \\
Vizcaino1 & .18 & .14 & .163 \\
Vizcaino2 & .15 & .13 & .149 \\
\hline
\end{tabular}

Note: The $P$ value indicates whether the overall specialization index statistically departs from a null model in which the number of interactions for each species is given by its abundance but interactions are assigned randomly.

${ }^{a} P<.0001$ in all cases.

species, then the number of hubs (generalist nurses) is necessarily low, as shown by the truncation of the powerlaw distribution (fig. 2). Truncation of a power law may happen when some interactions are forbidden for biological reasons (e.g., in seed dispersal networks, if a migrant bird arrives at the community when the fruiting period of a plant is over; Bascompte and Jordano 2007) or when the interactions are randomly produced but proportional to species abundance (Vázquez 2005). Although the number of interactions is correlated with species abundance in our communities, we have demonstrated that interactions are not randomly produced once species abundance is accounted for. In fact, a strong phylogenetic pattern exists in which facilitative interactions occur not at random but between distantly related species (Valiente-Banuet and Verdú 2007, 2008). In other words, facilitation between conspecifics or congeneric species that share similar regeneration niches and compete for similar resources is a forbidden interaction.

The network approach allows us to perceive that plant communities are structured not only by competition precluding some pairs of species from coexisting but also by facilitation allowing some others to coexist. Clearly, the studies between pairs of (or a few) species cannot inform us appropriately about the mechanisms acting at the community level, where a single nurse species may facilitate a significant number of other plant species (up to 48 species for Mimosa luisana in one of our study communities). In this situation of multiple-species coexistence, competitive effects between two species may be alleviated in the presence of a third species (see Callaway 2007 for examples of positive indirect interactions between competing plants). Indeed, growing empirical evidence from arid communities, including ours, indicates that multispecific vegetation clumps are maintained by a large proportion of positive interactions (Prentice and Werger 1985; Couteron and Kokou 1997; Eccles et al. 1999; Kéfi et al. 2007; Scanlon et al. 2007; Valiente-Banuet and Verdú 2008). Supporting this empirical evidence, a recent mathematical resource competition model has shown that a network of facilitative interactions among competing species may explain the coexistence of multiple species not only when facilitation predominates but even when competition outweighs facilitation (Gross 2008).

A promising approach to explaining the benefits of growing in multispecies mixtures would be to investigate how plant identity and species composition affect the soil community and, in turn, how soil diversity affects plant diversity (Wardle 2006). Indeed, most of our best nurses are rich in arbuscular mycorrhizal fungi (Camargo-Ricalde and Dhillion 2003; Camargo-Ricalde et al. 2003), and certain fungus species in these mycorrhizal networks may act as hubs with frequent connections to the network (Southworth et al. 2005). Ultimately, mycorrhizal networks may benefit all the "connected" plants by extending the resource acquisition network (Callaway 2007). Knowing how the above- and belowground networks are interconnected may help to unravel the processes underlying the structure of communities.

\section{Implications for Conservation}

The network approach may help predict local extinctions in the communities on the basis of the simple assumption that if nurse extinction causes a facilitated plant to lose its regeneration niche, the latter becomes extinct (Dunne 2006). Studies on plant-animal mutualisms show that the nested structure of the networks makes communities more robust to species extinction (Memmott et al. 2004). The high nestedness detected here suggests that communities shaped by facilitation are tolerant to the extinction of species. However, such communities may be endangered if extinction hits the most connected species, as shown by a simple extinction simulation (fig. 3, open circles). Fortunately, the most connected nurse species are also the most abundant species in the community, making facilitationshaped communities strongly resistant to extinction. Indeed, our simulations show that if the sequence of extinction occurs from the least to the most connected nurse species, the species diversity in the community is not significantly altered (fig. 3, filled circles). This is consistent with the findings of Valiente-Banuet et al. (2006), who described facilitation as a mechanism preserving global biodiversity. As in other communities governed by facilitation through multiple benefactor species (e.g., intertidal cordgrass bed communities; Altieri et al. 2007), the con- 

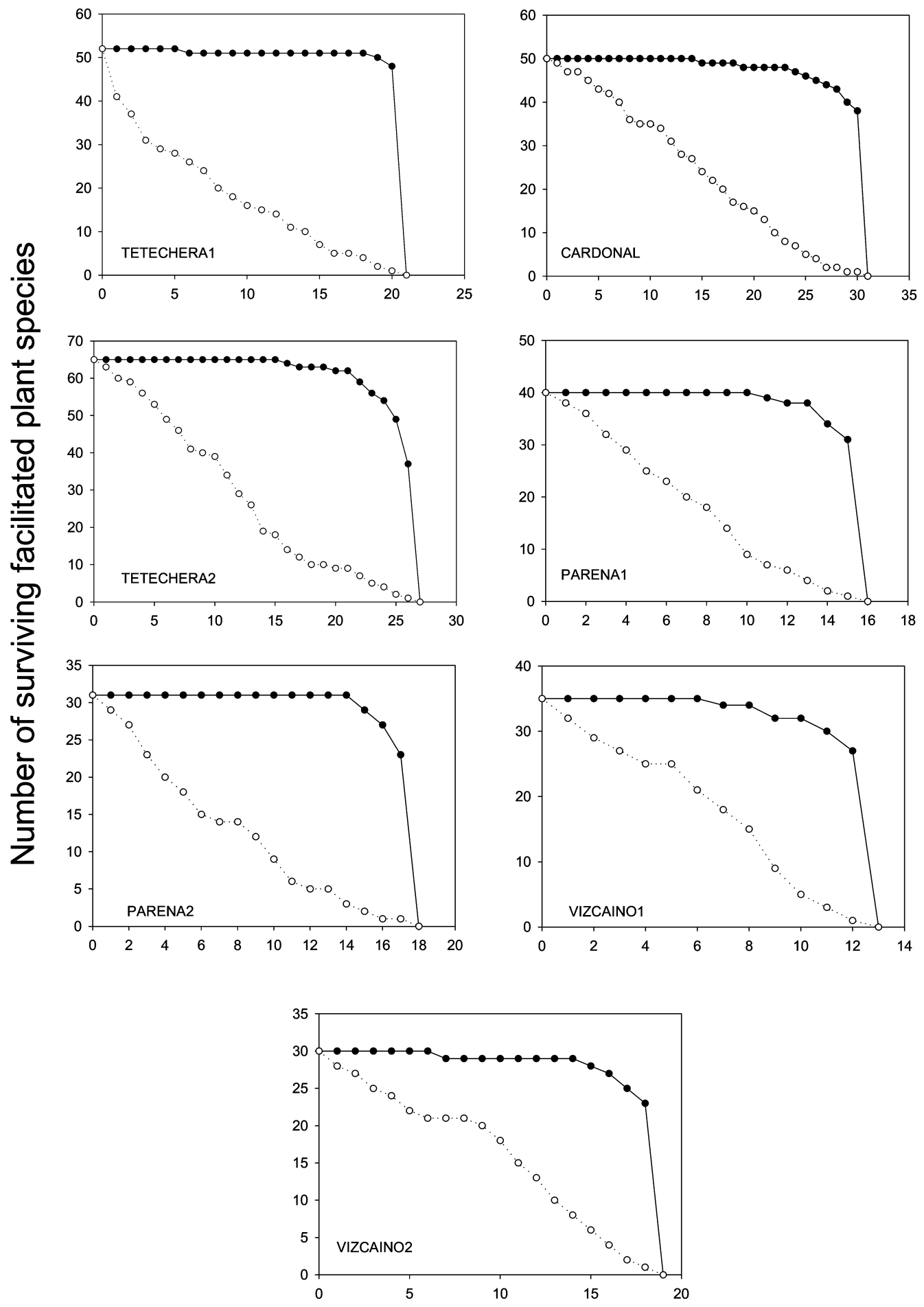

\section{Number of nurse species going extinct}

Figure 3: Simulations of coextinction processes of facilitated species under two scenarios of nurse extinction sequence. In the first scenario (filled circles), nurses are removed in order of connectedness from less connected to more connected, whereas the other scenario (open circles) follows the opposite extinction sequence. 
servation efforts must be allocated to the benefactor spe cies assembling the community.

At the same time, the highly nested structure of the network makes these communities prone to invasion of alien species. Many studies are now trying to unravel the mechanisms of biological invasions (Callaway and Aschehoug 2000; Stinson et al. 2006), and a network approach to the balance between facilitation and competition seem $\rightarrow$ especially valuable, because the sign of the interaction between a pair of species may change when a new species appears (Miller and Allen 1992; Hart et al. 2003; ValienteBanuet and Verdú 2008). These and other exciting avenue: in both theoretical and applied ecology open up as we move from the study of a reduced number of pairwise interactions to the network view describing the emerging properties arising in plant communities governed by facilitation.

\section{Acknowledgments}

D. Ackerly, J. Bascompte, M. C. Castellanos, J. P. Castillo, R. Cruz, P. García-Fayos, and P. Jordano provided valuabl $\rightarrow$ comments on the manuscript. J. P. Castillo, M. Morales, C. Rodríguez, C. Silva-Pereyra, C. Soberanes, and A. Vital helped with field samplings. Our research is funded by the Dirección General de Asuntos del Personal AcadémicoUniversidad Nacional Autónoma de México projects IN227605 and IN-224808 and by Programa Iberoamericanc de Ciencia y Tecnología para el Desarrollo, Subprograma Diversidad Biológica (project XII-6), for travel expenses to A.V.-B.
Brualdi, R. A., and J. G. Sanderson. 1999. Nested species subsets, gaps, and discrepancy. Oecologia (Berlin) 119:256-264.

Bruno, J. F. 2002. Causes of landscape-scale rarity in cobble beach plant communities. Ecology 83:2304-2314.

Bruno, J. F., and M. D. Bertness. 2001. Habitat modification and facilitation in benthic marine communities. Pages 201-220 in M. D. Bertness, S. D. Gaines, and M. E. Hay, eds. Marine community ecology. Sinauer, Sunderland, MA.

Bruno, J. F., J. J. Stachowicz, and M. D. Bertness. 2003. Inclusion of facilitation into ecological theory. Trends in Ecology \& Evolution 18:119-125.

Callaway, R. M. 1995. Positive interactions among plants. Botanical Review 61:306-349.

$\rightarrow-1998$. Are positive interactions species-specific? Oikos 82: 202-207.

- 2007. Positive interactions and interdependence in plant communities. Springer, Dordrecht.

$\rightarrow$ Callaway, R. M., and E. T. Aschehoug. 2000. Invasive plants versus their new and old neighbors: a mechanism for exotic invasion. Science 290:521-523.

Camargo-Ricalde, S. L., and S. S. Dhillion. 2003. Endemic Mimosa species can serve as mycorrhizal "resource islands" within semiarid communities of the Tehuacan-Cuicatlán Valley, Mexico. Mycorrhiza 13:129-136.

Camargo-Ricalde, S. L., S. S. Dhillion, and C. Jiménez-González. 2003. Mycorrhizal perennials of the "matorral xerófilo" and the "selva baja caducifolia" communities in the semiarid TehuacánCuicatlán Valley, Mexico. Mycorrhiza 13:77-83.

$\rightarrow$ Carrillo-García, Á., Y. Bashan, and G. J. Bethlenfalvay. 2000. Resource-island soils and the survival of the giant cactus, cardon, of Baja California Sur. Plant and Soil 218:207-214.

$\rightarrow$ Connell, J. H. 1983. On the prevalence and relative importance of interspecific competition: evidence from field experiments. American Naturalist 122:661-696.

$\rightarrow$ Couteron, P., and K. Kokou. 1997. Woody vegetation spatial patterns in a semiarid savanna of Burkina Faso, West Africa. Plant Ecology 132:211-227.

\section{Literature Cited}

Crawley, M. J. 1997. The structure of plant communities. Pages 475531 in M. J. Crawley, ed. Plant ecology. Blackwell Scientific, Oxford.

Dunne, J. A. 2006. The network structure of food webs. Pages 2786 in M. Pascual and J. A. Dunne, eds. Ecological networks: linking structure to dynamics in food webs. Oxford University Press, Oxford.

$\rightarrow$ Eccles, N. S., K. J. Esler, and R. M. Cowling. 1999. Spatial pattern analysis in Namaqualand desert plant communities: evidence for general positive interactions. Plant Ecology 142:71-85.

$\rightarrow$ Gotelli, N. J. 2000. Null model analysis of species co-occurrence patterns. Ecology 81:2606-2621.

$\rightarrow$ Gross, K. 2008. Positive interactions among competitors can produce species-rich communities. Ecology Letters 11:929-936.

$\rightarrow$ Guimarães, P. R., and P. Guimarães. 2006. Improving the analyses of nestedness for large sets of matrices. Environmental Modelling and Software 21:1512-1513.

Guimarães, P. R., V. Rico-Gray, S. F. dos Reis, and J. N. Thompson. 2006. Asymmetries in specialization in ant-plant mutualistic networks. Proceedings of the Royal Society B: Biological Sciences 273: 2041-2047.

$\rightarrow$ Guimarães, P. R., C. Sazima, S. F. dos Reis, and I. Sazima. 2007. The nested structure of marine cleaning symbiosis: is it like flowers and bees? Biology Letters 3:51-54. 
$\rightarrow$ Hart, M. M., R. J. Reader, and J. N. Klironomos. 2003. Plant co existence mediated by arbuscular mycorrhizal fungi. Trends in Ecology \& Evolution 18:418-423.

$\rightarrow$ Jordano, P., J. Bascompte, and J. M. Olesen. 2003. Invariant properties in coevolutionary networks of plant-animal interactions. Ecology Letters 6:69-81.

$\rightarrow$ Kéfi, S., M. Rietkerk, C. L. Alados, Y. Pueyo, V. P. Papanastasis, A. Elaich, and P. C. de Ruiter. 2007. Spatial vegetation patterns and imminent desertification in Mediterranean arid ecosystems. $\mathrm{Na}$ ture 449:213-217.

Levins, R., and R. Lewontin. 1985. The dialectical biologist. Harvarc $\rightarrow$ University Press, Cambridge, MA.

$\rightarrow$ McAuliffe, J. R. 1988. Markovian dynamics of simple and complex desert plant communities. American Naturalist 131:459-490.

$\rightarrow$ Memmott, J., N. M. Waser, and M. V. Price. 2004. Tolerance o pollination networks to species extinctions. Proceedings of the Royal Society B: Biological Sciences 271:2605-2611.

Miller, S. L., and E. B. Allen. 1992. Mycorrhizae, nutrient translo $\rightarrow$ cation and interactions between plants. Pages 301-332 in M. F. Allen, ed. Mycorrhizal functioning, an integrative plant-fungal process. Chapman \& Hall, New York.

$\rightarrow$ Miller, T. E. 1994. Direct and indirect species interactions in an early old-field plant community. American Naturalist 143:1007-1025.

$\rightarrow$ Montoya, J. M., S. L. Pimm, and R. V. Solé. 2006. Ecological networks and their fragility. Nature 442:259-264.

$\rightarrow$ Olesen, J. M., J. Bascompte, Y. Dupont, and P. Jordano. 2006. The smallest of all worlds: pollination networks. Journal of Theoretical Biology 240:270-276.

$\rightarrow$ Prentice, I. C., and M. J. A. Werger. 1985. Clump spacing in a desert dwarf shrub community. Vegetatio 63:133-139.

$\rightarrow$ Puerta-Piñero, C., J. M. Gómez, and R. Zamora. 2006. Speciesspecific effects on topsoil development affect Quercus ilex seedlin performance. Acta Oecologica 29:65-71.

$\rightarrow$ Scanlon, T. M., K. K. Caylor, S. A. Levin, and I. Rodríguez-Iturbe. 2007. Positive feedbacks promote power-law clustering of Kalahari vegetation. Nature 449:209-212.

Shreve, F. 1951. Vegetation of the Sonoran Desert. Carnegie Institution of Washington Publication 591. Carnegie Institution, Washington, DC.

$\rightarrow$ Southworth, D., X-H. He, W. Swenson, C. S. Bledsoe, and W. R Horwath. 2005. Application of network theory to potential mycorrhizal networks. Mycorrhiza 15:589-595.

$\rightarrow$ Stachowicz, J. J. 2001. Mutualism, facilitation, and the structure of ecological communities. BioScience 51:235-246.
Stinson, K. A., S. A. Campbell, J. R. Powell, B. E. Wolfe, R. M. Callaway, G. C. Thelen, S. G. Hallett, D. Prati, and J. N. Klironomos. 2006. Invasive plant suppresses the growth of native tree seedlings by disrupting belowground mutualisms. PLoS Biology 4 : e140.

Tirado, R., and F. I. Pugnaire. 2005. Community structure and positive interactions in constraining environments. Oikos 111:437444.

Ulrich, W., and N. J. Gotelli. 2007. Null model analysis of species nestedness patterns. Ecology 88:1824-1831.

Valiente-Banuet, A., and E. Ezcurra. 1991. Shade as a cause of the association between the cactus Neobuxbaumia tetetzo and the nurse plant Mimosa luisana in the Tehuacán Valley, Mexico. Journal of Ecology 79:961-970.

Valiente-Banuet, A., and M. Verdú. 2007. Assembly through facilitation can increase the phylogenetic diversity of plant communities. Ecology Letters 10:1029-1036.

2008. Temporal shifts from facilitation to competition occur between closely related taxa. Journal of Ecology 96:489-494.

Valiente-Banuet, A., P. Dávila, R. J. Ortega, M. C. Arizmendi, J. L. León, A. Breceda, and J. Cancino. 1995. Influencia de la evolución del paisaje en una pendiente de piedemonte en una vegetación de cardonal de Pachycereus pringlei en Baja California Sur, México. Investigaciones Geográficas, número especial 3:101-113.

$\rightarrow$ Valiente-Banuet, A., A. Vital, M. Verdú, and R. M. Callaway. 2006. Modern Quaternary plant lineages promote diversity through facilitation of ancient Tertiary lineages. Proceedings of the National Academy of Sciences of the USA 103:16812-16817.

van de Koppel, J., A. H. Altieri, B. R. Silliman, J. F. Bruno, and M. D. Bertness. 2006. Scale-dependent interactions and community structure on cobble beaches. Ecology Letters 9:45-50.

Vázquez, D. P. 2005. Degree distribution in plant-animal mutualistic networks: forbidden links or random interactions? Oikos 108:421426.

Vázquez, D. P., and M. A. Aizen. 2006. Community-wide patterns of specialization in plant-pollinator interactions revealed by null models. Pages 200-219 in N. M. Waser and J. Ollerton, eds. Plantpollinator interactions: from specialization to generalization. University of Chicago Press, Chicago.

Wardle, D. A. 2006. The influence of biotic interactions on soil biodiversity. Ecology Letters 9:870-886.

Associate Editor and Editor: Monica A. Geber 